\title{
Direct determination of highly size-resolved turbulent particle fluxes with the disjunct eddy covariance method and a 12 - stage electrical low pressure impactor
}

\author{
A. Schmidt and O. Klemm \\ Institute of Landscape Ecology - Climatology, University of Münster, Robert-Koch-Str. 26, 48149 Münster, Germany \\ Received: 8 April 2008 - Published in Atmos. Chem. Phys. Discuss.: 20 May 2008 \\ Revised: 30 September 2008 - Accepted: 21 November 2008 - Published: 12 December 2008
}

\begin{abstract}
During summer 2007, turbulent vertical particle mass and number fluxes were measured for a period of 98 days near the city centre of Münster in north-west Germany. For this purpose, a valve controlled disjunct eddy covariance system was mounted at $65 \mathrm{~m}$ a.g.l. on a military radio tower. The concentration values for 11 size bins with aerodynamic diameters $(D 50)$ from 0.03 to $10 \mu \mathrm{m}$ were measured with an electrical low pressure impactor. After comparison with other fluxes obtained from $10 \mathrm{~Hz}$ measurements with the classical eddy covariance method, the loss of information concerning high frequent parts of the flux could be stated as negligible. The results offer an extended insight in the turbulent atmospheric exchange of aerosol particles by highly size-resolved particle fluxes covering 11 size bins and show that the city of Münster acts as a relevant source for aerosol particles.
\end{abstract}

Significant differences occur between the fluxes of the various particle size classes. While the total particle number flux shows a pattern which is strictly correlated to the diurnal course of the turbulence regime and the traffic intensity, the total mass flux exhibits a single minimum in the evening hours when coarse particles start to deposit.

As a result, a mean mass deposition of about $10 \mathrm{mg} \mathrm{m}^{-2}$ per day was found above the urban test site, covering the aerosol size range from $40 \mathrm{~nm}$ to $2.0 \mu \mathrm{m}$. By contrast, the half-hourly total number fluxes accumulated over the lower ELPI stages range from $-4.29 \times 10^{7}$ to $+1.44 \times 10^{8}$ particles $\mathrm{m}^{-2} \mathrm{~s}^{-1}$ and are clearly dominated by the sub-micron particle fraction of the impactor stages with diameters between $40 \mathrm{~nm}$ and $320 \mathrm{~nm}$. The averaged number

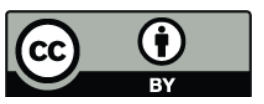

Correspondence to: A. Schmidt (andres.schmidt@uni-muenster.de) fluxes of particles with diameters between 2.0 and $6.4 \mu \mathrm{m}$ show lower turbulent dynamics during daytime and partially remarkably high negative fluxes with mean deposition velocities of $2 \times 10^{-3} \mathrm{~m} \mathrm{~s}^{-1}$ that appear temporary during noontime and in the evening hours.

\section{Introduction}

During the last decade much progress could be archived in the research about properties of atmospheric aerosols and their interactions with the environment. Nevertheless, there are still a lot of uncertainties, especially concerning the amount of their influence on the earth's energy budget (e.g. Andreae et al., 2005; Yu et al., 2006; Hatzianastassiou et al., 2007; Koren et al., 2008). Particulate matter plays important roles in many atmospheric processes by influencing and driving numerous chemical reactions and through physical interaction with the incoming as well as the outgoing radiation. Furthermore, aerosol particles have an effect on the formation and characteristics, e.g. droplet number, of clouds by functioning as condensation nuclei (Hatzianastassiou et al., 1998; VanReken et al., 2003; Seinfeld and Pandis, 2006; Altaratz et al., 2008). Furthermore, the health threats caused by aerosols are well proven and demand further and differentiated research (e.g. Donaldson et al., 1998; Ito et al., 2006). Due to these extensive and partially insufficiently understood climatological and toxicological aspects, the measurement of aerosols in general and the mostly turbulent exchange of particulate matter between the atmosphere and the underlying surface moved into the focus of research. Several studies have focused on the aspect of turbulent atmospheric exchange of aerosols based on different approaches. These

Published by Copernicus Publications on behalf of the European Geosciences Union. 
proceedings comprise the obtainment of vertical concentration gradients (Petelski, 2003), the relaxed eddy accumulation (REA) method (Gaman et al., 2004; Pryor et al., 2007), the direct eddy covariance (EC) technique (Vong et al., 2004; Mårtensson et al., 2006; Fratini et al., 2007; Ruuskanen et al., 2007), or various modelling approaches (Kramm and Dlugi, 1994; Held et al., 2006). An extensive and comparative review of studies about turbulent particle atmospheresurface exchange, at least over vegetated areas during the last decades, is given by Pryor et al. (2008).

Since devices for highly size-resolved particle analyses are often not fast enough to measure concentrations continuously with $10 \mathrm{~Hz}$ (or faster) as needed for the classic EC method, present studies are forced to concentrate on specific compounds, or are constricted to specific particle size fractions. Hence, the experimental determination of size-segregated turbulent particle fluxes is difficult and still sparsely explored. Depending on their sizes, the general properties of aerosols differ significantly in terms of their chemical reactivity or their role concerning the radiation budget. Last but not least, the ultrafine particles are much more harmful, concerning their influence on human's health (Schwartz et al., 1996; Donaldson et al., 2002; Pope et al., 2002). With regard to these facts, a deeper understanding of size-resolved particle concentration and transport, which occurs mostly by turbulent fluxes, is urgently needed. Due to these actual challenges on the one hand and the reduced capability of the instrumentation on the other hand, the direct measurement of size-resolved turbulent particle fluxes with the EC method has to be replaced by other approaches.

An advanced approach using fewer samples within one averaging interval is the disjunct eddy covariance (DEC) method, originally described by Haugen (1978). Using the DEC method, the scalar (in our case size-resolved particle concentrations) is measured with lower sample frequencies as limited by the response time of the employed measurement devices.

The deviations of DEC measured scalar fluxes, compared to turbulent fluxes calculated from measurements with truly high time resolution, are within acceptable limits and DEC measurements still achieve the requirements of the eddy covariance theory (Lenschow et al., 1994). Hence, as a novel and promising approach, the DEC method can be applied for the determination of size-resolved turbulent vertical particle fluxes directly by applying an electrical low pressure impactor (ELPI) for the size-resolved particle concentrations as put forward by Held et al. (2007).

The ELPI allows near real-time measurements of particle size distributions with a time resolution of several seconds (Marjamäki et al., 2000). Within this study we applied a valve controlled DEC system for the determination of highly size-segregated turbulent fluxes of aerosol particles, separated into 11 size classes with aerodynamic geometric mean diameters $(D i)$ from $40 \mathrm{~nm}$ through $6.4 \mu \mathrm{m}$.

\section{Methods and materials}

\subsection{Site description and instrumentation}

The city of Münster, with a population of about 272000 inhabitants, is located in north-west Germany. In contrast to the predominantly agriculturally managed surrounding, the city itself exhibits major emissions from traffic, densely populated residential areas, power plants, small to medium size industrial plants, and long-range transport (Gietl et al., 2008; Schmidt et al., 2008). We built an experimental setup to measure the turbulent exchange of particles between the urban surface and the urban boundary-layer. The setup, consisting of a 3-D-ultrasonic anemometer YOUNG $81000 \mathrm{~V}$ (R. M. Young Company, Traverse City, Michigan 49686, USA), an open path infrared $\mathrm{CO}_{2} / \mathrm{H}_{2} \mathrm{O}$ analyser $L I-7500$ (LICOR, Inc., Lincoln, Nebraska 68504, USA), an electrical low pressure impactor (Outdoor ELPI, Dekati Ltd., 33700 Tampere, Finland), and a valve-controlled particle inlet was mounted on top of a military radio tower at $65 \mathrm{~m}$ a.g.l. from 30 May through 6 September 2007 near the city centre of Münster. The measurement height was about $40 \mathrm{~m}$ above the rooftops of the surrounding buildings. This height of the setup ensured that the measurements were not directly influenced by single, nearby urban particle sources that could have disturbed the concentration measurements, but were related to footprints that represent the city region. During the regionally predominant south-westerly wind directions the tower station lies downwind of the residential and industrial sections of the city. With respect to these main wind directions, the particle inlet, consisting of a $45 \mathrm{~cm}$ stainless steel capillary with an inner diameter of $3 \mathrm{~mm}$, was mounted together with the LI-7500 sensor head in north-easterly direction, in a distance of about $15 \mathrm{~cm}$ behind the measuring region of the 3-D ultrasonic anemometer. Conductive silicone tubing led from the steel capillary into a pinch valve box. A second conductive silicone tubing with an in-line HEPA particle filter led to the bypass of the fast pinch valve with a response time of $20 \mathrm{~ms}$ (Series 384, ASCO Scientific, Florham Park, NJ, USA). The valve control software which records the switching signals was also used to record the $10 \mathrm{~Hz}$ wind data. Thus, by pinching either the sample tubing or the clean air tubing, the valve was used to selectively lead either ambient sample air or particle-free filtered air to the ELPI. With a sample flow rate of $251 \mathrm{~min}^{-1}$ a dead volume of about $2 \%$ of the total sample volume remained in the inlet tubing. Arranged behind a conductive silicone tubing with a length of $2.5 \mathrm{~m}$ and an inner diameter of $7.9 \mathrm{~mm}$ led from the software controlled switch-valve to the ELPI on the platform directly below the measurement pole as outlined in Fig. 1. At the bottom of the tower, a laptop PC was used to record the measurement data and to run the ELPI operational software (ELPIVI 4.0, Dekati Ltd.) as well as the valve control software. 


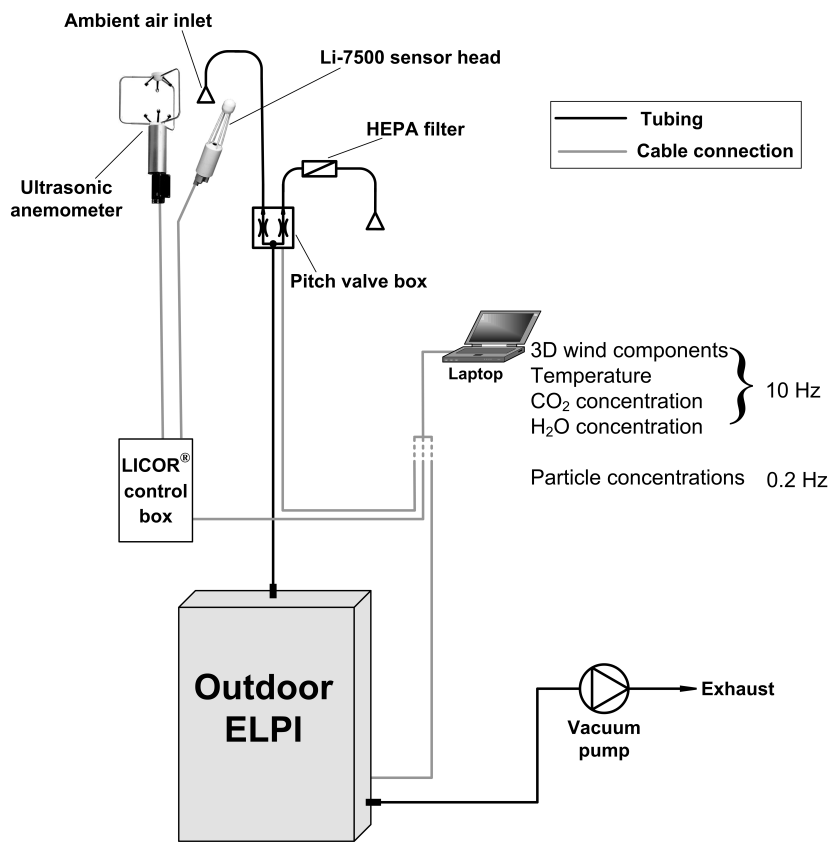

Fig. 1. Schematic overview of the DEC measurement setup including the ultrasonic anemometer, open path $\mathrm{CO}_{2} / \mathrm{H}_{2} \mathrm{O}$ analyser, pinch-valve unit with sample inlet and clear air inlet, electrical low pressure impactor, and the Laptop-PC with the device control software and data acquisition software.

\subsection{The electrical low pressure impactor}

The ELPI allows the near-real-time measurement of airborne particle size distributions in the size range from $7 \mathrm{~nm}$ through $10 \mu \mathrm{m}$ diameter, using 12 separate channels. Within the ELPI the particles are electrically charged when passing a unipolar corona charger in the inlet system. Here, the particles are positively charged by colliding with much smaller gas ions that originate from an electrical corona discharge. After fragmentation by their aerodynamic diameter in the 12stage cascade impactor, the charged particles are detected in the respective stages by sensitive multi-channel electrometers that register the currents as induced by the impaction of the charged particles on the impactor collection plates. Hence, the aerosol particles can be counted with respect to their size. For this purpose, specific charger efficiency functions and kernel functions are applied that transform the measured currents to the required values such as particle number distributions, volume distribution, or mass distribution including all available size classes.

The ELPI can be run in different sensitivity modes that affect the measurement range and the signal response time of the ELPI i.e., the shortest interval between two consecutive samples. During the measurements that were performed during this study, the instrument range with a maximum current of $100 \mathrm{pA}$ has been selected as tested and recommended by Held et al. (2007). This matches with the particle concentra-
Table 1. Stages of the Electric Low Pressure Impactor (ELPI) with $D 50$ cutpoints determined by the manufacturer and the aerodynamic geometric mean diameters $D i$ (rounded to 2 significant decimal places).

\begin{tabular}{lll}
\hline ELPI Stage \# & $\begin{array}{l}\text { Aerodynamic } \\
\text { cut-off diameter } \\
D 50(\mu \mathrm{m})\end{array}$ & $\begin{array}{l}\text { Aerodynamic } \\
D i(\mu \mathrm{m})\end{array}$ \\
\hline 1 & 0.0282 & 0.040 \\
2 & 0.0558 & 0.073 \\
3 & 0.0954 & 0.12 \\
4 & 0.159 & 0.20 \\
5 & 0.265 & 0.32 \\
6 & 0.387 & 0.49 \\
7 & 0.621 & 0.77 \\
8 & 0.960 & 1.2 \\
9 & 1.62 & 2.0 \\
10 & 2.42 & 3.1 \\
11 & 4.04 & 6.4 \\
12 (inlet) & 10.06 & - \\
\hline
\end{tabular}

tions at the urban test site and offers a response time of $4.8 \mathrm{~s}$ that appeared to be appropriate for the DEC measurements. The functionality of the ELPI has already been described within several related publications in detail (e.g. Keskinen et al., 1992; Marjamäki et al., 2000; Baron and Willeke, 2001; Virtanen et al., 2001; Marjamäki et al., 2005). Due to known problems of the filter stage, which tends to slightly overestimate the number particle concentration (Pakkanen et al., 2006; Kerminen et al., 2007), only the measured values of the 11 size bins from 0.03 through $10 \mu \mathrm{m}$ (aerodynamic cutpoint diameter D50) were used for further calculations within this study. The analysed particle size bins of the ELPI are listed in Table 1.

The $D i$ of a stage, used for the calculations of the respective mass concentrations and therefore mass fluxes, is defined as the geometric mean given by

$D i_{n}=\sqrt{D 50_{n} \cdot D 50_{n+1}}$.

Here $n$ is the stage number, $D i$ the aerodynamic geometric mean diameter and $D 50_{n}$ is the median of the aerodynamic diameter (i.e. cutpoint) of stage $n$.

In order to determine the turbulent particulate mass exchange also above the city area, the expected particle density was derived from several analyses of Berner type impactor measurements in the city area of Münster (Gietl et al., 2008). A mean particle density of $1.5 \mathrm{~g} \mathrm{~cm}^{-3}$ can be assumed as a good approximation to be used for the particle mass calculations. For this purpose the stage-related particle masses were calculated under the simplified assumption of a spherical shape with respect to the corresponding aerodynamic geometric mean diameters of the ELPI stages (Table 1). 
When calculating the mass concentrations from the current values registered by the ELPI electrometers, the fine particle losses have to be taken into account. Due to diffusion, small particles sometimes impact on upper stages where they do not yet belong and account for an adulterated increased counting of coarser particles. Due to the cubic theoretical relation between the particle radius and its mass, this leads to problems when obtaining the particle mass distributions. As the number of these misclassified particles is relatively small but the mass contribution per particle of the upper stages is relatively large, some of the transformations from particle number concentrations to particle mass concentrations are not reliable. The mass values are overestimated for the coarser particle size bins above $\mathrm{PM}_{2.5}$. Therefore, size-resolved particle mass fluxes were only obtained for the reliable range of the ELPI stages 1 to 9 (i.e. $40 \mathrm{~nm}$ through $2 \mu \mathrm{m})$.

\subsection{DEC determination of the aerosol particle fluxes}

Due to the relatively slow analysis procedures for particle size distributions using an ELPI, the determination of highly size-resolved, turbulent particle fluxes bears some relevant problems for the application of the classical EC method with its commonly used sampling rates in the range of 10 and $20 \mathrm{~Hz}$. The DEC method offers a possibility to obtain turbulent fluxes when using slower instruments by allowing increased measurement intervals between two samples, but keeping the sampling duration itself short enough to capture turbulent fluctuations (Lenschow et al., 1994). In our case (as detailed below), the concentration scalars of the 11 particle size bins were measured simultaneously by opening the pinch-valve controlled ambient air inlet every $5 \mathrm{~s}(\Delta t)$ for a sampling duration of $0.4 \mathrm{~s}(t s)$.

The data record interval of the ELPI has been set to $1 \mathrm{~s}$, which is the lowest interval for reliable data acquisition. During the post-processing, these $1 \mathrm{~Hz}$ data samples of the ELPI were summarised over the respective $5 \mathrm{~s}$ measurement interval to yield the final particle concentrations for each stage. These particle concentrations, which are representative for the sampling duration of $0.4 \mathrm{~s}$, were used to calculate the covariance with the temporal corresponding velocity of the vertical wind component. Thus, the DEC values were calculated with an effective time resolution of $0.2 \mathrm{~Hz}$. In combination with the short sampling time of $0.4 \mathrm{~s}$ these settings are still adequate to determine turbulent fluxes (Lenschow et al., 1994; Held et al., 2007).

\subsection{Quality assessment and DEC data analysis}

Concerning some statistical criteria such as the stationarity of the time series or meteorological restrictions, the application of the DEC method demands the same high data quality criteria as the commonly used classic EC method. In order to test and assure the data quality for the flux computations, the quality criteria given by Foken et al. (2004) and Foken (2006) were adopted. For this purpose the quality tests and data corrections, including coordinate rotation for the streamline fit (Wilczak et al., 2001), consideration of density fluctuations by the WPL-correction algorithm (Webb et al., 1980), timelag correction by application of the maximum crosscovariance method, stationarity check, and the calculation of the integral turbulence characteristics (ITC) were carried out with an in-house software developed for flux time series analyses.

A minimum friction velocity of $0.15 \mathrm{~m} \mathrm{~s}^{-1}$, additionally applied for the verification of a well developed turbulence regime especially during the night time, was systematically obtained with a neural network modelling-test as introduced by Schmidt et al. (2008). Due to the position of the LI-7500 sensor head and the ambient air inlet, both installed nearby the ultrasonic anemometer, the north-easterly wind direction was disturbed by the instruments. This concerned about $3 \%$ of the measurement data. The affected data were excluded from further calculations. Furthermore, there are some requirements concerning the ELPI particle counts.

In particular, a minimum number of registered particles is necessary, in order to gain measurement signals that exceed the noise of the ELPI electrometers with a selected signal-tonoise ratio of at least 3 . For the applied sensitivity range of $100 \mathrm{pA}$ the upper limit of the signal noise level of the ELPI is \pm 15 fA (Dekati Ltd., 2006). The respective minimum numbers are different for each stage and were respected during data analysis by excluding values that exhibit such low current values and therefore too low derived particle numbers.

After filtering the dataset according to the described eddy covariance data requirements, limiting meteorological conditions, outliers, too low particle concentrations, and instrument malfunctions, 3500 reliable half-hourly data records of high quality containing all input variables (i.e. temperature, wind components, $\mathrm{CO}_{2}$ concentration, water vapour concentration and particle concentration, divided into 11 size bins) were available for further analyses.

The used half-hourly block time interval is considered to be a good compromise between the need to cover long time series in order to catch the relevant frequencies contributing to the flux, and the need to shorten the time series to guarantee at least near steady-state conditions (Finnigan et al., 2003; Foken et al., 2004; Foken, 2006). The applicability of this averaging period has also been approved for particle fluxes in other studies (e.g. Mårtensson et al., 2006; Fratini et al., 2007; Pryor et al., 2007).

The half-hourly measurement data files comprising the wind components, the (sonic) temperature, the $\mathrm{CO}_{2}$ concentration, and the water vapour concentration contain 18000 raw data values that were recorded with $10 \mathrm{~Hz}$, whereas the half-hourly data files of the particle concentrations contain 360 raw data values, recorded with a temporal resolution of $0.2 \mathrm{~Hz}$. 
In order to combine and synchronise these data for the covariance calculations, the $10 \mathrm{~Hz}$ wind velocity values were averaged over the ELPI sampling intervals. The averaging began with the valve open signal. These averages, particularly those for the vertical wind component $w$, were arranged to be perfectly synchronous to the corresponding particle concentration datasets as integrated over the $0.4 \mathrm{~s}$ following the opening of the ambient air inlet. Therefore, each of the resulting half-hourly averaged particle flux values was calculated from 360 data records by using these new combined DEC files.

During the $5 \mathrm{~s}$ measurement intervals, the filtered air that flowed through the system over $4.6 \mathrm{~s}$ causes no measurement signals that exceed the noise of the ELPI electrometer channels. By contrast, the total current signals registered by the ELPIVI 4.0 software can be clearly recognised after opening the sample inlet ( $t s=0.4 \mathrm{~s}$ ) for the ambient air flow, every $5 \mathrm{~s}$ (Fig. 2).

Therefore, the total current values accumulated over all available ELPI stages offered a well defined adjustment signal for exact determination of the integration limits during data analyses.

During the post-processing, the recorded "valve open" signal was used to mark the $0.4 \mathrm{~s}$ sampling intervals to yield the corresponding mean vertical wind velocity. According to Held et al. (2007), who accomplished several laboratory experiments with a prototype valve-controlled ELPI DEC system, the applied measurement interval of $5 \mathrm{~s}$ and the chosen sampling duration of $0.4 \mathrm{~s}$ appeared to be a good compromise between the need of high resolution samples for the determination of turbulent fluxes and the need of a reliable obtainment of the size-segregated particle concentrations with the ELPI.

The commonly used EC equation for the mean covariance (i.e. fluxes $F$ ) for an averaging interval of $30 \mathrm{~min}$ (for instance),

$F_{30 \min }=\overline{c^{\prime} w^{\prime}}$

has to be modified for the DEC application into

$$
\begin{aligned}
& F_{30 \min }=\frac{1}{n-1} \sum_{m=1}^{n}\left(\left(\sum_{k=1}^{5} c_{k}\right)_{1 \mathrm{~Hz}}-\bar{c}_{30 \mathrm{~min}}\right)_{m} \\
& \cdot\left(\left(\frac{1}{4} \sum_{j=1}^{4} w_{j}\right)_{10 \mathrm{~Hz}}-\bar{w}_{30 \mathrm{~min}}\right)_{m}
\end{aligned}
$$

and applied separately to each aerosol particle size bin. Here $n$ is the number of samples per averaging interval, $c$ is the concentration value recorded with $1 \mathrm{~Hz}$ and $w$ is the vertical wind velocity. Hence, within an interval of $30 \mathrm{~min}$ we yield 360 datasets with which the covariance is calculated. These $n$ datasets (in our case 360 ) consist of the 5-s, integrated particle concentration records of each size bin on the one hand and the contemporaneous 0.4 -s averages of the $10 \mathrm{~Hz}$ vertical

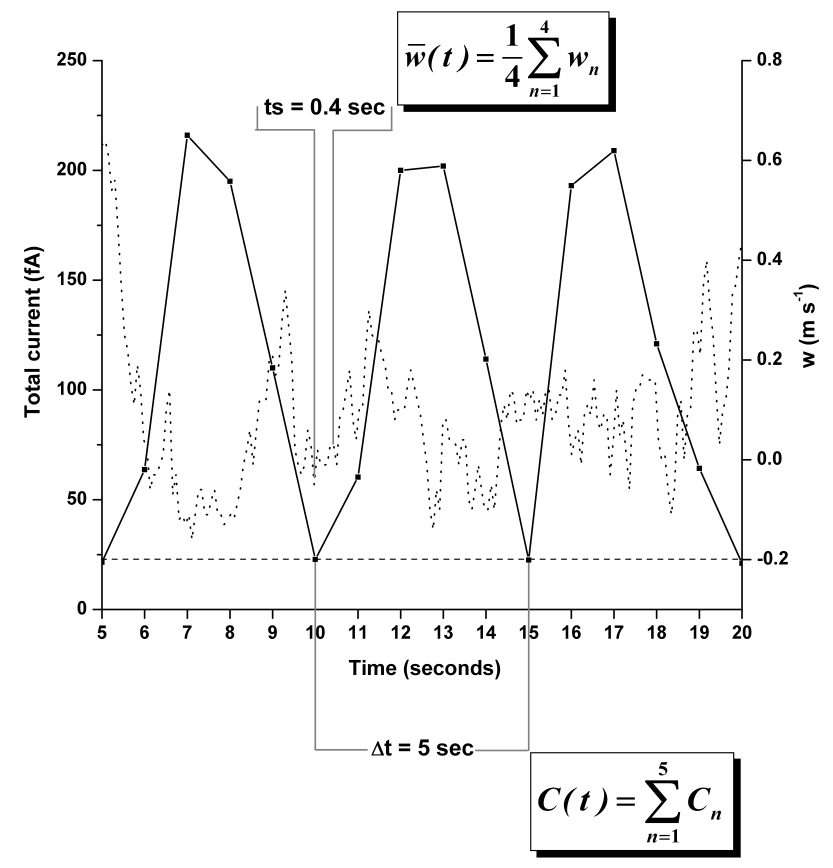

Fig. 2. The total current time series used for the determination of the integration limits (continuous line). The dotted line shows the $10 \mathrm{~Hz}$ values of the vertical wind velocity $w$ and the dashed line marks the applied border for acceptance of measurement values, which is three times the electrometer noise level of the ELPI.

wind velocity records on the other hand. The apostrophes in Eq. (2) denote the deviations of discrete measurements from the average (e.g. of a $30 \mathrm{~min}$ averaging period).

Since the sampling rate is reduced in comparison to the quasi-continuous $10 \mathrm{~Hz}$ measurements, the DEC flux measurements contain an increased uncertainty. However, the sampling rate induced flux bias, relative to the flux averages derived from $10 \mathrm{~Hz}$ measurements, is negligible. Similar results concerning the correlation of the half-hourly average values from direct eddy covariance data and the corresponding disjunct eddy covariance fluxes were obtained in other studies which also accomplished comparative field experiments ore partially a more detailed analysis of the effect of sampling rates on the average flux results with respect to the theoretical backgrounds (Haugen, 1974; Kaimal and Gaynor, 1983; Lenschow et al., 1994; Rinne et al., 2000; Bosveld and Beljaars, 2001; Rinne et al., 2008; Hendriks et al., 2008).

However, the discrete sampling of continuous values implies an error of the derived fluxes that can, according to Buzorius et al. (2003), be calculated by:

$\delta F=\sqrt{\sum_{i=1}^{n} \frac{w_{i}^{2} c_{i}^{2}}{n^{2}} \cdot\left[\frac{\delta\left(w_{i}\right)}{w_{i}}\right]^{2}+\sum_{i=1}^{n} \frac{w_{i}^{2} c_{i}}{n^{2}} \cdot \frac{1}{Q \cdot t s}}$.

Here $Q$ is the sampling flow rate, $t s$ the sampling period, and $\delta(w)$ gives the uncertainty of the ultrasonic anemometer measurements. Hence, the first term under the square 


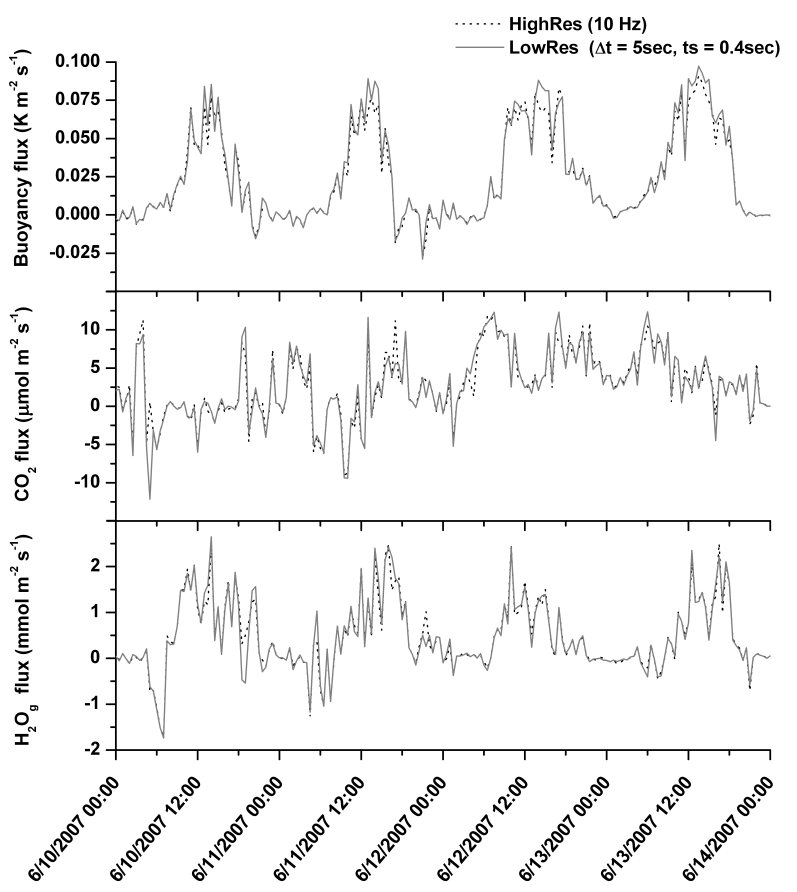

Fig. 3. Continuous period of the turbulent flux time series derived from the $10 \mathrm{~Hz}$ EC measurements and the corresponding $0.2 \mathrm{~Hz}$ DEC measurements during June 2007.

root in Eq. (4) gives the error contribution related to the wind measurements and the second term accounts for the error due to the limited particle counting statistics. With respect to the generally lower particle concentrations in the upper stages the derived flux values contain higher uncertainty than the corresponding fluxes of the smaller particle fractions. With the already described values used for this study, maximum errors of about $3 \%$ for the obtained fluxes of the super-micron sizes (particle diameters $>1 \mu \mathrm{m}$ ) that passed the previous selected quality criteria, have to be considered.

\section{Results and discussion}

3.1 Comparison of fluxes originating from EC and DEC calculations

After the necessary corrections and quality assessment procedures described in Sect. 2.4, the covariance of $w$ and the different particle concentrations could be obtained throughout the measurement period above the city area of Münster by applying Eq. (3). As the temporal resolution of the samples is reduced in comparison to a conventional EC algorithm, the reliability and accuracy of the experimental results in form of the turbulent vertical fluxes need to be approved as well as possible.
For this purpose, the variables which were available with a temporal resolution of $10 \mathrm{~Hz}$, namely the $\mathrm{CO}_{2}$ concentration, the wind components, water vapour concentration, and the air temperature were averaged and re-sampled by taking one $0.4 \mathrm{~s}$ mean value every $5 \mathrm{~s}$. Here, the valve-open marks were used to set the start points of the averaging intervals. Hence, we yield $0.2 \mathrm{~Hz}$ records similar to the 11 simultaneous concentrations used for the particle flux calculations.

Since $10 \mathrm{~Hz}$ data records were available for some variables, the fluxes of buoyancy, carbon dioxide, and water vapour were also calculated using 18000 raw data values for each half-hourly turbulent vertical flux value. Hence, we were able to compare these synchronous half-hourly flux values calculated from the artificial DEC raw data values with the synchronous EC flux values calculated from the highly resolved $10 \mathrm{~Hz}$ data records.

An example of the respective turbulent vertical fluxes for a several time series of several days is shown in Fig. 3. The DEC flux values of the buoyancy flux, $\mathrm{CO}_{2}$ flux and water vapour flux are very similar to those derived from the $10 \mathrm{~Hz}$ values. The DEC flux time series appear partially smoothed or show minor differences compared to the corresponding EC flux values.

Hence, the loss of information concerning the high frequent parts of the turbulent transport appears to be mostly negligible, indicating that the DEC derived flux values can be treated as reliable in principle.

Due to the fact that the single samples are taken within $0.4 \mathrm{~s}$ every $5 \mathrm{~s}$, the record frequency is $0.4 \mathrm{~Hz}$ whereas the spectral resolution is defined by the sampling duration and thus is $2.5 \mathrm{~Hz}$. Hence, the Nyquist frequency which determines the spectral resolution of the data is $1.25 \mathrm{~Hz}$. Therefore, the loss of spectral information is acceptable when using the DEC method.

To obtain quantified information about the obtained differences between the fluxes calculated from $10 \mathrm{~Hz}$ measurements and the fluxes obtained with the artificial DEC data that exhibit lower temporal resolution, the averaged percentage deviations $\delta F_{\text {High Low }}$ and the roots of the mean squared errors (RMSE) are calculated over a subset of 1344 halfhourly mean flux values which is equivalent to an amount of four weeks of data with,

$\operatorname{RMSE}=\sqrt{\frac{1}{n} \cdot \sum_{i=1}^{n}\left(F_{i}^{H}-F_{i}^{L}\right)^{2}}$,

and

$\delta F_{\text {High Low }}=\frac{100}{n} \cdot \sum_{i=1}^{n} \frac{F_{i}^{H}-F_{i}^{L}}{F_{i}^{H}}$.

Here $n$ is the number of data points, $F_{i}^{H}$ is the EC flux value calculated from the highly temporal resolved $10 \mathrm{~Hz}$ measurements and $F_{i}^{L}$ the corresponding DEC value, calculated from the low resolved time series of the $30 \mathrm{~min}$ averaging interval 
Table 2. Obtained differences between the $10 \mathrm{~Hz}$ EC fluxes and the respective DEC flux values.

\begin{tabular}{lll}
\hline Flux variable & RMSE & $\delta \mathrm{F}_{\text {High Low }}$ \\
\hline Carbon dioxide & $2.28 \mu \mathrm{mol} \mathrm{m}^{-2} \mathrm{~s}^{-1}$ & $1.6 \%$ \\
Water vapour & $0.48 \mathrm{mmol} \mathrm{m}^{-2} \mathrm{~s}^{-1}$ & $2.1 \%$ \\
Buoyancy & $7.28 \times 10^{-3} \mathrm{~K} \mathrm{~m}^{-2} \mathrm{~s}^{-1}$ & $0.7 \%$ \\
\hline
\end{tabular}

number $i$. The results are given in Table 2 and show a good agreement of the respective half-hourly flux values.

Thus, it can be concluded that the DEC sampling interval is appropriate to account for the relevant variations of the selected scalar. Furthermore, the intervals between the samples are long enough to respect the response time of the relatively slow ELPI device (Held et al., 2007). The deviations show a slight underestimation of the DEC fluxes probably due to the high frequent turbulence parts which can not be resolved using the applied sampling interval $t s$. Overall, these results show, that fluxes determined with the DEC are a very good approximation of the fluxes obtained with the direct EC.

\subsection{Time series of size-resolved particle fluxes}

Within the discussed measurement period during spring and summer 2007 the turbulent vertical particle fluxes of 11 size bins were obtained by the DEC method with an ELPI, as described above. The number fluxes are clearly dominated by the sub-micron size bins (particle diameters $<1 \mu \mathrm{m}$ ) which exceed the simultaneous number fluxes of the super-micron size bins by orders of magnitude (Fig. 4).

The half-hourly total number fluxes summarised over all 11 analysed ELPI stages ranging from $-4.29 \times 10^{7}$ to $+1.44 \times 10^{8}$ particles $\mathrm{m}^{-2} \mathrm{~s}^{-1}$ are dominated by the submicron particle fraction with diameters between 0.04 and $0.20 \mu \mathrm{m}$ (not shown).

A diurnal pattern is apparent for the aerosol number flux time series (Fig. 4). This applies especially to the smaller size fractions (i.e. stages 1 to 6 ), whereas the exchange fluxes (downward versus upward) of coarse particles (stages 10 and 11) is almost balanced within a diurnal cycle.

To validate the supposed diurnal pattern of the particle fluxes and to justify a further analysis of diurnal averages, a spectral analysis of the block average flux time series was accomplished. After fast Fourier transformation of the autocorrelation function of the resulting total particle number flux time series (stages 1 to 11 ), the power spectrum confirms a distinct diurnal pattern of the particle number fluxes. Nevertheless, power spectra have to be analysed carefully in order to avoid erroneous conclusions through over-interpretation of found periodicities or even artefacts. Due to the nonevanescent autocorrelation of the total number flux time series, the significance has to be tested with an underlying the-

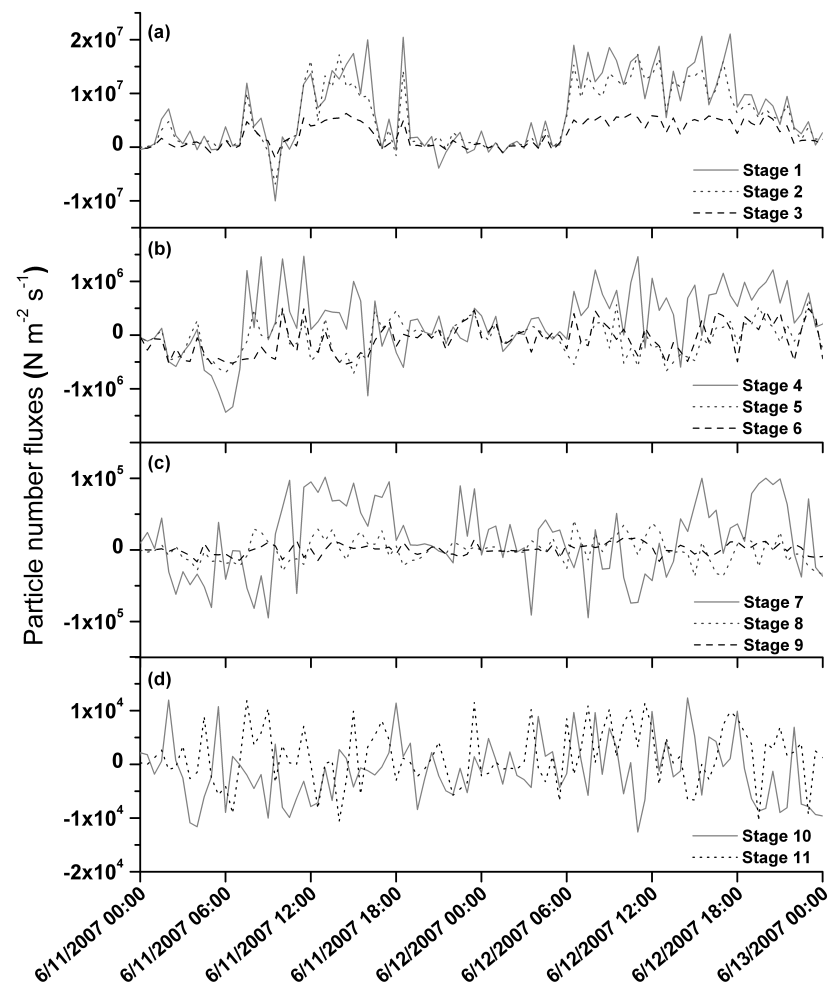

Fig. 4. Example of size-segregated particle number fluxes during two complete exemplary days in June 2007. Note different scaling of y-axes for the four panels.

oretical red noise spectrum instead of a white noise background level. Therefore, the theoretical red-noise spectrum was determined based on a modelled Markov-chain according to Gilman et al. (1963) and Priestley (1981),

$S_{R}(k)=\frac{1-r_{1}^{2}}{1+r_{1}^{2}-2 r_{1} \cos (k \pi / M)}$.

Here, $S_{R}$ are the red-noise spectrum values, $M$ is the maximum lag of the Fourier transformed autocorrelation function, $r_{1}$ is the autocorrelation coefficient at a relative shift of 1 , and $k$ an increasing integer value from 2 to $M$, corresponding to the respective frequency or period.

Afterwards, the theoretical Markovian spectrum can be used to determine the significance of the obtained spectrum values by a $\chi^{2}$ - distribution test (Panofsky and Brier, 1958).

The result shows, that the 24-h peak exceeds the line marking the selected $95 \%$ confidence level by far (Fig. 5).

As a conclusion of the preliminary spectral significance test the $24 \mathrm{~h}$ - period can be regarded as significant and meaningful in terms of the temporal behaviour of the particle number fluxes and allows further interpretations of diurnal patterns.

Furthermore, this peak can be interpreted as validation of a relation between the particle flux above the urban measurement site with the diurnal pattern of the human activities that 


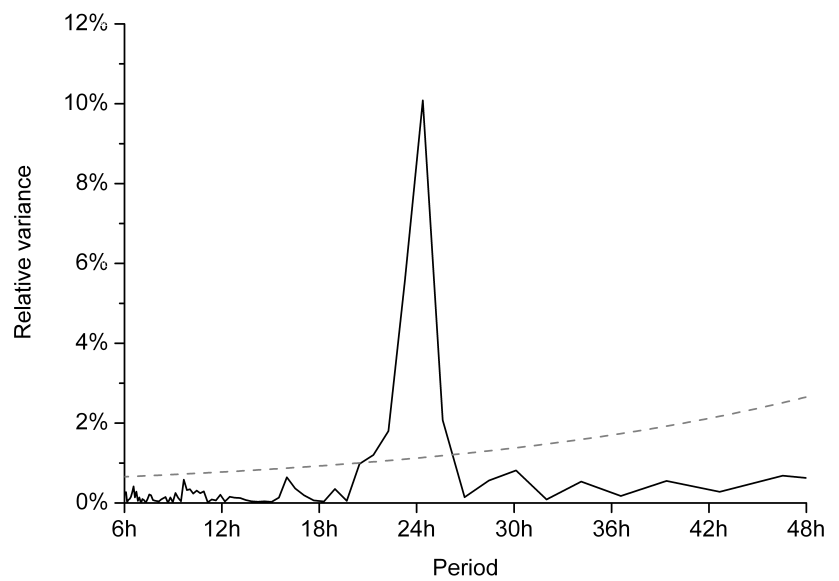

Fig. 5. Power spectrum of a continuous part of the time series containing the half-hourly total number fluxes. The dashed line shows the respective $95 \%$ confidence level.

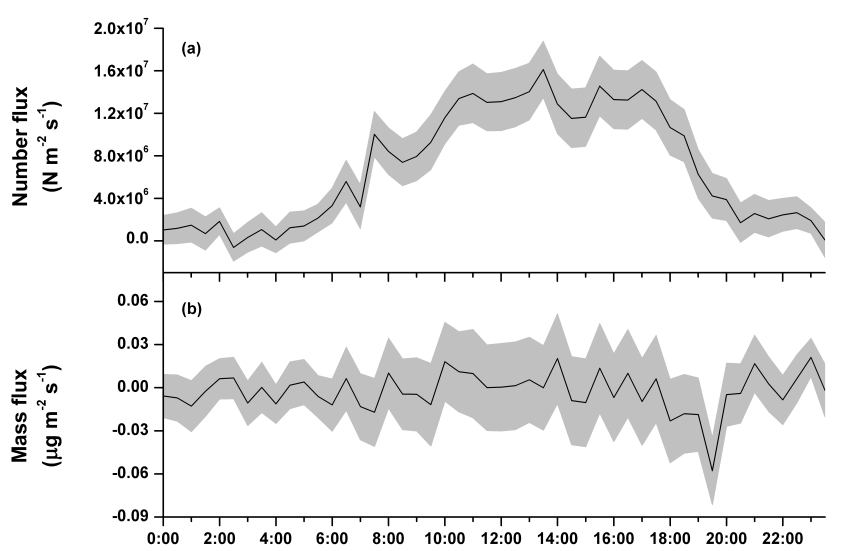

Fig. 6. Averaged diurnal aerosol number fluxes (a) and aerosol mass fluxes (b) each accumulated over the ELPI stages 1 to 9 (i.e. $D i=0.04$ to $2.0 \mu \mathrm{m})$. The shaded area marks the $\pm 1 \sigma$ deviation, representing the day-to-day variability.

influence the particle concentrations for example through rush-hour traffic, and the meteorological conditions that drive the turbulence (e.g. temperature and stability), both exhibiting well known and clear diurnal patterns (e.g. Longley et al., 2004; Mårtensson et al., 2006; Schmidt et al., 2008).

\subsection{Diurnal averages of particle number and mass fluxes}

To yield reasonable daily averages in terms of statistic representativeness with simultaneous consideration of virtually steady seasonal conditions, the averaging interval was chosen to include 8 consecutive weeks during July and August 2007 with similar meteorological conditions.

Figure 6 shows the average diurnal total number flux and the respective accumulated mass flux. Since the particle mass calculations are only reliable up to the sizes of stage 9 both,

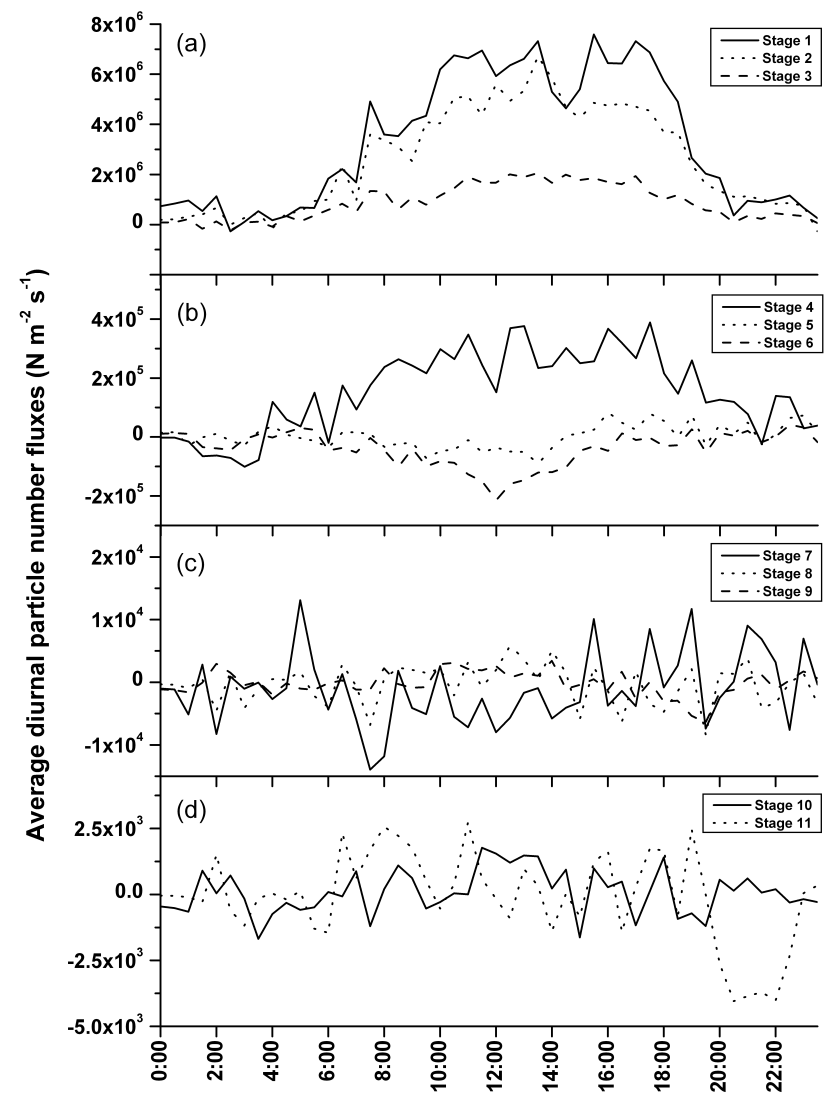

Fig. 7. The mean daily particle number fluxes of the particles with Di's from $40 \mathrm{~nm}$ up to $6.4 \mu \mathrm{m}$.

the particle number fluxes and the particle mass fluxes were accumulated over the size bins that correspond to these stages (1-9), in order to yield comparable patterns.

The total particle number flux exhibits a pattern with 3 peaks (about 7:30, 13:00, and 16:00 local time) which are embedded in the daily main peak that is obviously related to the known diurnal cycle of atmospheric turbulence development (e.g. Stull, 1988; Arya, 2001).

This superposition of meteorological parameters (development of turbulence) and anthropogenic parameters (traffic emissions) that both influence the particle flux values has also been observed in other studies which are concerned with particle fluxes above urban areas (Dorsey et al., 2002; Mårtensson et al., 2006).

In contrast, the averaged total particle mass flux shows a lower response to the dynamics of turbulence in the daytime and increased deposition fluxes that appear temporary in the evening.

The size-segregated average diurnal particle number fluxes (stages 1-11) are shown in Fig. 7, while Fig. 8 shows the respective size-resolved particle mass fluxes of the particles registered in the ELPI stages 1-9. Significant differences between the fluxes of the sub-micron size bins and those of the super-micron sizes can be recognized. 
With regard to the fluxes of particles with aerodynamic mean diameters from 3.1 to $6.4 \mu \mathrm{m}$ (stages 10 and 11), it has to be kept in mind that, due to the relative small particle numbers, the measured concentration values contain a greater statistical uncertainty. This led to a reduction of the number of concentration values which passed the quality test and were available for flux calculations. Thus, the numbers of single flux values which were used for the mean daily flux calculations are reduced by $9 \%$ compared to the numbers of flux values which were available for the lower ELPI stages 1 to 9. Nevertheless, the fluxes of the coarse particles (stages 10 and 11) were calculated from high quality data but exhibit an increased statistical uncertainty and should be interpreted with care.

The accumulated mean fluxes of the small particle size classes of about $0.1 \mu \mathrm{m}$ and below (stage 1 to 3 ) are obviously dependent on the turbulence regime. This is supported by the high coefficients of the Spearman rank correlation analyses with the respective stability parameter $z / L$ $(r=-0.87)$ and the friction velocity $u_{*}(r=0.81)$.

Moreover, two peaks are remarkable in the diurnal course of the small particles of stage 1 to 3 which appear in temporal correspondence with the climax of rush-hour traffic at about 7:30 in the morning and 16:30 in the afternoon (Fig. 7a).

In this context, the fluxes of the particles registered in stage 6 are remarkable. The respective fluxes lead to a relevant deposition that occurs during noontime, after the strong emission period of smaller particles during the morning rush-hour traffic.

The negative fluxes of these particles with a $D i$ of $0.49 \mu \mathrm{m}$ can be recognised clearly in Figs. $7 \mathrm{~b}$ and in $8 \mathrm{~b}$ showing its minimum at 12:00. Such observations can probably be explained by coagulation events and particle growth of the smaller particles, emitted during morning rush-hour time and the deposition of the newly built and coarser particles afterwards. The mean deposition velocity of the corresponding aerosol particles reaches its maximum of $0.21 \mathrm{~cm} \mathrm{~s}^{-1}$ during noontime at 12:00.

In spite of the much lower number contributions of the super-micron size aerosols, the corresponding mass fluxes show a reverse relation in terms of parts at the total exchange. This is a consequence of the cubic relation between particle radius and its derived mass and is amplified by the exponentially increasing differences between the consecutive ELPI stages concerning the aerodynamic mean diameters. Thus, in contrast to the particle number fluxes, the mass fluxes are clearly dominated by the particles with aerodynamic diameters $>0.5 \mu \mathrm{m}$. The mostly upward direction of the measured fluxes that belong to the lower stages 1 to 5 and the more frequent negative fluxes of the larger aerosols $(D i \geq 490 \mathrm{~nm})$ are shown in the mean mass flux time series (Fig. 8). Especially the turbulent mass deposition in the evening hours with respect to the stages 8 and 9 are notable and contribute considerably to the diurnal aerosol mass balance.

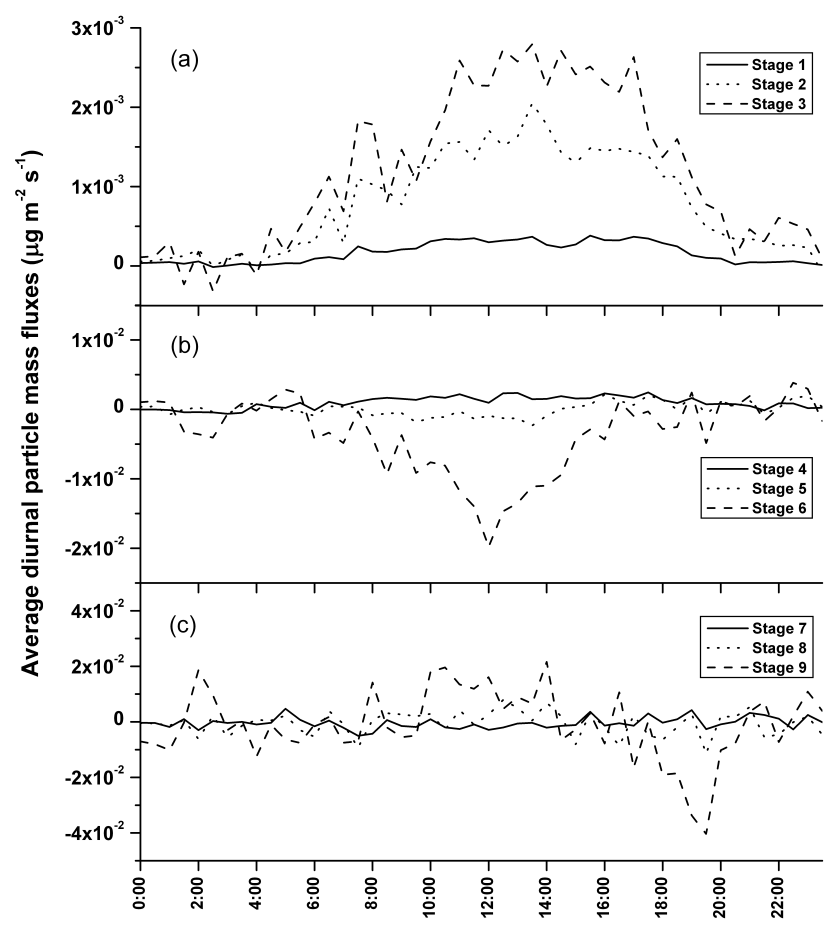

Fig. 8. The mean daily aerosol mass fluxes of particles with $D i$ ranging between $40 \mathrm{~nm}$ and $2.0 \mu \mathrm{m}$ (i.e. ELPI stages 1-9).

Since the measurement site is placed in a spatially relatively homogenous area in terms of land use within the covered footprint area, no significant differences between particle concentrations in connection with the prevailing wind directions occurred during the 98 days of the measurement campaign.

\subsection{Variations of particle fluxes related to urban activity cy- cles}

In order to obtain precise information of the relation between traffic emissions and urban particle fluxes, the datasets were divided into two observational groups, one group representing the weekdays from Monday through Friday, the other group representing Sundays and holidays, respectively. Since the traffic volume on Saturdays is somewhere in between the weekday traffic volume and Sunday traffic volume, the Saturdays were left out of this analysis to yield clear results about the role of the traffic exhausts concerning the turbulent particle fluxes.

A noteworthy difference between the averaged daily particle fluxes on Sundays and on weekdays can be obtained, particularly with regard to the accumulated particle number fluxes of stage 1 to 3 (Fig. 9).

The decreasing fluxes after the morning rush-hour and after the second peak that appears during the afternoon rushhour traffic, are typical patterns of the urban particle fluxes 


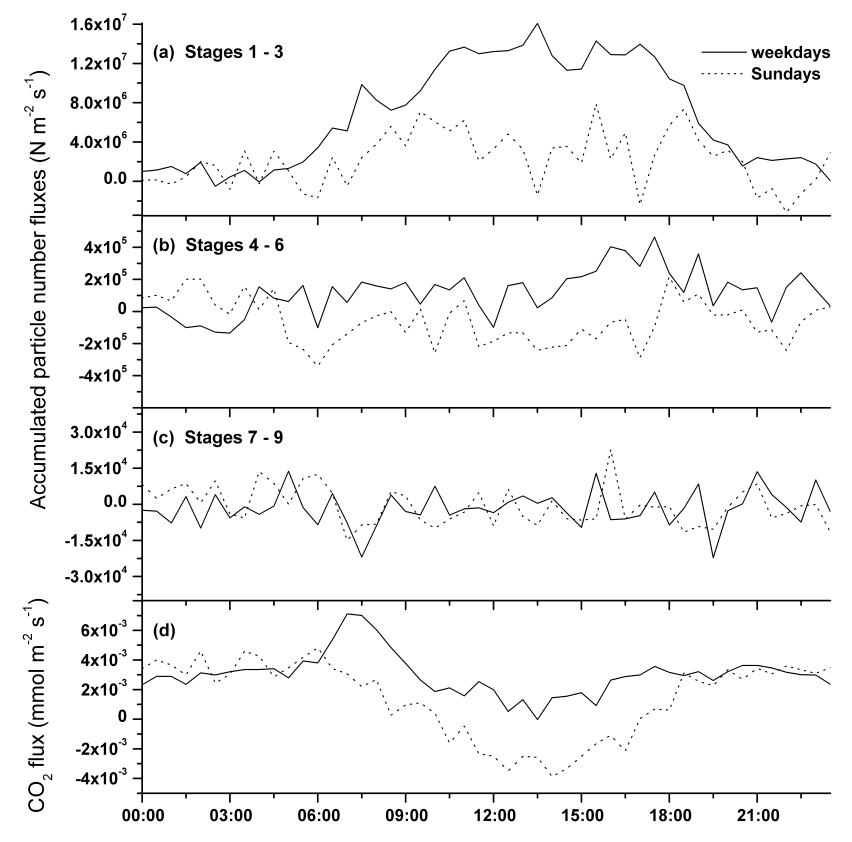

Fig. 9. Comparison of the averaged daily fluxes of different particle sizes (number fluxes) and carbon dioxide on weekdays and Sundays measured during summer 2007 above the urban study site.

or other urban, mostly anthropogenic emissions such as $\mathrm{CO}_{2}$ (e.g. Velasco et al., 2005; Vogt et al., 2006; Schmidt et al., 2008).

These characteristic temporary turbulent emission events do not occur on Sundays or holidays. The simultaneously obtained $\mathrm{CO}_{2}$ fluxes, as measured on weekdays, exhibit a diurnal course that reflects the traffic volume clearly. By contrast, the mean flux values on Sundays indicate the effect of the biological net uptake of $\mathrm{CO}_{2}$ by the vegetation within the city area, which is not strong enough to cause mean negative fluxes during the weekdays. This provides evidence of the complex structure of atmospheric exchanges in urban areas that are mostly influenced by anthropogenic emissions on the one hand and net uptake of $\mathrm{CO}_{2}$ by scattered vegetated areas on the other hand. The weekend fluxes of the small particles exhibit no diurnal cycle with negative values during noon time, as the $\mathrm{CO}_{2}$ fluxes do (Fig. 9d), because there is no vegetation-related uptake for the particles.

Nevertheless, since the massive temporary particle emissions from traffic do not appear on Sundays, a similar behaviour with reduced fluxes on Sundays and missing rushhour peaks can be found in the diurnal cycles of the fine particles with aerodynamic diameters between 0.04 and $0.12 \mu \mathrm{m}$ (stages 1 to 3, Fig. 9 a and d). By contrast, the coarser particles of the upper stages 4 to 6 also show a change in the amount of flux values, but not in their relative diurnal pattern (Fig. 9b). Furthermore, aerosol particles with diameters ranging from 0.77 to $2 \mu \mathrm{m}$ (stages 7 to 9 ) not even show a sig-

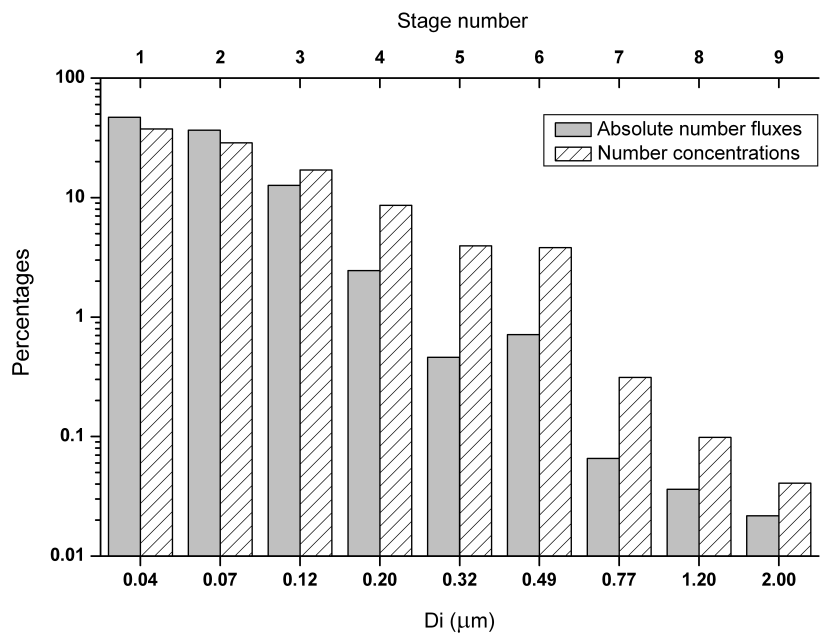

Fig. 10. Percentage contributions of the different particle sizes to the total number flux and concentrations, respectively.

nificant reduction of the amount of daily turbulent exchange on Sundays and holidays compared to weekdays (Fig. 9c). This additionally supports the assumption that the respective particles (stage 1 to 3 ) are mainly originating from the local traffic emissions that cause this diurnal pattern in the turbulent vertical fluxes.

Thus, the reduction of the traffic amount obviously accounts for the most important differences in the examined urban turbulent particle exchange. As a consequence, it can clearly be stated that the traffic pollution emission is the most important source of the particles that belong to the size bins with geometric mean diameters ranging from $40 \mathrm{~nm}$ to $0.12 \mu \mathrm{m}$ (stages 1 to 3 ).

Similar relations between particle size to traffic volume were also found during several studies that focused on the composition of motor particle exhausts or related ambient air concentrations (e.g. Maricq et al., 1999; Harris and Maricq, 2001; Pakkanen et al., 2006).

To determine the contributions of the single size bins at the total atmospheric exchange above the urban area during the measurement period without respecting the flux direction, the absolute values (irrespective of their signs) of the mean turbulent exchanges per day were accumulated for each particle size bin. The relative contributions of these numbers to the respective totals are shown in Fig. 10.

The absolute turbulent exchange percentages confirm the special role of the particle size class around $0.49 \mu \mathrm{m}$ (stage 6 ), again. The concentration percentage and the flux percentage exceed the expected values under the assumption of a log-linear distribution (Fig. 10). The special role of this size class has already been shown above for the averaged diurnal fluxes as presented in Figs. 7 and 8. 
Table 3. Averaged daily turbulent particle exchange of different size bins.

\begin{tabular}{llll}
\hline Stage \# & $D i(\mu \mathrm{m})$ & $\begin{array}{l}\text { Net turbulent mass } \\
\text { exchange }\left(\mathrm{mg} \mathrm{m}^{-2} \mathrm{~d}^{-1}\right)\end{array}$ & $\begin{array}{l}\text { Net turbulent number } \\
\text { exchange }\left(\mathrm{N} \mathrm{m}^{-2} \mathrm{~d}^{-1}\right)\end{array}$ \\
\hline 1 & 0.040 & $0.69 \pm 1.92 \times 10^{-03}$ & $1.36 \times 10^{13} \pm 3.79 \times 10^{10}$ \\
2 & 0.073 & $3.25 \pm 1.06 \times 10^{-02}$ & $1.06 \times 10^{13} \pm 3.47 \times 10^{10}$ \\
3 & 0.12 & $4.89 \pm 3.56 \times 10^{-02}$ & $3.61 \times 10^{12} \pm 2.63 \times 10^{10}$ \\
4 & 0.20 & $4.02 \pm 1.17 \times 10^{-02}$ & $6.40 \times 10^{11} \pm 1.86 \times 10^{9}$ \\
5 & 0.32 & $0.18 \pm 3.30 \times 10^{-04}$ & $6.87 \times 10^{9} \pm 1.26 \times 10^{8}$ \\
6 & 0.49 & $-14.97 \pm 9.61 \times 10^{-02}$ & $-1.62 \times 10^{11} \pm 1.04 \times 10^{9}$ \\
7 & 0.77 & $-1.68 \pm 1.47 \times 10^{-02}$ & $-4.69 \times 10^{9} \pm 4.11 \times 10^{7}$ \\
8 & 1.2 & $-2.17 \pm 4.08 \times 10^{-02}$ & $-1.60 \times 10^{9} \pm 3.01 \times 10^{7}$ \\
9 & 2.0 & $-4.10 \pm 1.05 \times 10^{-01}$ & $-6.50 \times 10^{8} \pm 1.66 \times 10^{7}$ \\
10 & 3.1 & - & $3.45 \times 10^{8} \pm 1.64 \times 10^{7}$ \\
11 & 6.4 & - & $-3.58 \times 10^{8} \pm 1.21 \times 10^{7}$ \\
& $\Sigma$ & $-9.89 \pm 2.02 \times 10^{-02}$ & $2.83 \times 10^{13} \pm 5.78 \times 10^{10}$ \\
\hline
\end{tabular}

Furthermore, we calculated that the ultrafine particle sizes (stages 1 and 2) account for $84 \%$ of the total daily number fluxes. By contrast, these particle sizes account for a lower percentage of $66 \%$ concerning the respective daily number concentrations during the measurement period.

In contrast to the data in Fig. 10 the values in Table 3 give the mean daily balances through turbulent vertical fluxes with respect to the particle sizes and flux directions. The total uncertainties for the mean daily values are obtained by application of the law of error propagation after calculating the errors of each $30 \mathrm{~min}$ flux value according to Eq. (4).

A mean mass deposition of $9.9 \mathrm{mg} \mathrm{m}^{-2}$ per day was found above the urban study site covering the particle sizes from $40 \mathrm{~nm}$ up to $2.0 \mu \mathrm{m}$ determined by the aerodynamic geometric mean diameters of the ELPI stages 1-9. The direction of the obtained average fluxes shows the positive daily balance of the turbulent atmospheric exchange of particles with aerodynamic geometric mean diameters from $40 \mathrm{~nm}$ to $0.32 \mu \mathrm{m}$ and the negative turbulent exchange balance of the coarse aerosols of stage 6 to 12 (with the exception of stage 10).

The contribution of the particles with $D i$ of about $0.5 \mu \mathrm{m}$ to the total deposited mass are again emphasised by the values in Table 3 as well as the high parts of the sub-micron particle sizes at total daily mean number fluxes.

\section{Summary and conclusion}

The applied DEC method in connection with the ELPI is a relatively novel experimental method and enabled us to obtain highly size-resolved turbulent fluxes of urban aerosols for the first time, separated into 11 size bins. A mean positive turbulent exchange of $2.8 \times 10^{13}$ particles per $\mathrm{m}^{2}$ per day, as summarised over all 11 size classes ( $40 \mathrm{~nm}$ to $6.4 \mu \mathrm{m})$, or $9.9 \mathrm{mg} \mathrm{m}^{-2}$ per day accumulated over the $D i$-range from 0.04 to $2.0 \mu \mathrm{m}$ was obtained. The mostly positive turbulent number fluxes, measured above the city area, show that the city of Münster acts as a considerable source for aerosol particles.

Moreover, the results give an extended insight into the turbulent vertical particle exchange and show some general patterns which are clearly related to anthropogenic activities. A comparison of the fluxes of different particle sizes shows that the daily courses differ considerable.

In more detail, the data provide evidence for the dependencies between the turbulent particle fluxes of the sub-micron particle sizes and traffic. The emission of small particles and the conspicuous turbulent deposition of coarser particles during noontime exhibit some remarkable temporal relations. The massive traffic emissions of the fine particles with aerodynamic midpoint diameters from 40 to $120 \mathrm{~nm}$ (stage 1 to 3) are followed by a correlated deposition of particles with aerodynamic diameters of $0.49 \mu \mathrm{m}$, registered in the ELPI stage 6 . The stable periodicity of these coherences suggests the presumption that such observations can be explained by particle growth processes within the sub-micron particle size range.

Hence, a causal relation can be assumed but needs further studies that focus on the particle growth and the related turbulent transport to further support these conclusions. Furthermore, a better size-resolution, especially in the supermicron range of the $\mathrm{PM}_{10}$ fraction is an important challenge for further instrument development and future experimental research in particle flux dynamics. Also, the advanced development of the simultaneous determination of the chemical composition of size-resolved particle samples, e.g. by application of mass-spectrometry, is necessary for the under- 
standing of the atmospheric cycles of aerosols and moreover, in order to make an important step forward in the field of particle source determination and the chemical compositions of aerosols.

Acknowledgements. We gratefully acknowledge the Deutsche Forschungsgemeinschaft for financial support of this work (DFG, K1623/8-1) and L. Harris for language editing of the manuscript.

We further thank T. Wrzesinsky for the development of the software applied for the wind data record and valve control of the DEC System. The authors also would like to thank A. Hörl, S. Lieberts, M. Siewecke and P. Stein of the Manfred-von-Richthofen casern in Münster for the permission to use the military radio tower, and P. Sulmann for his support during the installations at this measurement site.

\section{Edited by: K. Hämeri}

\section{References}

Altaratz, O., Koren, I., Reisin, T., Kostinski, A., Feingold, G., Levin, Z., and Yin, Y.: Aerosols' influence on the interplay between condensation, evaporation and rain in warm cumulus cloud, Atmos. Chem. Phys., 8, 15-24, 2008, http://www.atmos-chem-phys.net/8/15/2008/.

Andreae, M. O., Jones, C. D., and Cox, P. M.: Strong present-day aerosol cooling implies a hot future, Nature, 435, 1187-1190, 2005.

Arya, S. P.: Introduction to Micrometeorology, Second Edition, Academic Press, San Diego, 420 pp., 2001.

Baron, P. A. and Willeke, K.: Aerosol Measurement - Principles, Techniques, and Applications, Second Edition, John Wiley \& Sons, 1172 pp., 2001.

Bosveld, F. C. and Beljaars, A. C. M.: The impact of sampling rate on eddy-covariance flux estimates, Agr. Forest Meteorol., 109, 39-45, 2001.

Buzorius, G., Rannik, Ü., Nilsson, E. D., Vesala, T., and Kulmala, M.: Analysis of dry deposition velocity measurement techniques for particles smaller than $100 \mathrm{~nm}$, J. Aerosol Sci., 34, 747-764, 2003.

Dekati Ltd.: ELPI user manual, Version 4.01, Tampere, Finland, 152 pp., 2006.

Donaldson, K., Lia, X. Y., and MacNeea, W.: Ultrafine (nanometre) particle mediated lung injury, J. Aerosol Sci., 29, 553-560, 1998.

Donaldson, K., Brown, D., Clouter, A., Duffin, R., MacNee, W., Renwick, L., Tran, L., and Stone, V.: The pulmonary toxicology of ultrafine particles, J. Aerosol Med., 15, 213-220, 2002.

Dorsey, J. R., Nemitz, E., Gallagher, M. W., Fowler, D., Williams, P. I., Bower, K. N., and Beswick, K. M.: Direct measurements and parameterisation of aerosol flux, concentration and emission velocity above a city, Atmos. Environ., 36, 791-800, 2002.

Foken, T., Göckede, M., Mauder, M., Mahrt, L., Amiro, B. D., and Munger, J. W.: Post-field data quality control, in: Lee, X., Massman, W., and Law, B.: Handbook of Micrometeorology: A Guide for Surface Flux Measurement and Analysis, Kluwer Academic Publishers, Dordrecht, 181-208, 2004.

Foken, T.: Angewandte Meteorologie Mikrometeorologische Methoden, Second Edition, Springer, Berlin, Heidelberg, 326 pp., 2006.
Finnigan, J. J., Clement, R., Malhi, Y., Leuning, R., and Cleugh, H. A.: A re-evaluation of long-term flux measurement techniques. Part I: Averaging and coordinate rotation, Bound.-Lay. Meteorol., 107, 1-48, 2003.

Fratini, G., Ciccioli, P., Febo, A., Forgione, A., and Valentini, R.: Size-segregated fluxes of mineral dust from a desert area of northern China by eddy covariance, Atmos. Chem. Phys., 7, 2839-2854, 2007, http://www.atmos-chem-phys.net/7/2839/2007/.

Gaman, A., Rannik, Ü., Aalto, P., Pohja, T., Siivola, E., Kulmala, M., and Vesala, T.: Relaxed Eddy Accumulation System for Size-Resolved Aerosol Particle Flux Measurements. J. Atmos. Ocean. Tech., 21, 933-943, 2004.

Gietl, J. K., Tritscher, T., and Klemm, O.: Size-segregated analysis of $\mathrm{PM}_{10}$ at two sites, urban and rural, in Münster (Germany) using five-stage Berner type impactors, Atmos. Environ., 42, 57215727, 2008.

Gilman, D. L., Fuglister, F. J., and Mitchell Jr., J. M.: On the Power Spectrum of "Red Noise", J. Atmos. Sci., 20, 182-184, 1963.

Harris, S. J. and Maricq, M. M.: Signature size distributions for diesel and gasoline engine exhaust particulate matter, J. Aerosol Sci., 32, 749-764, 2001.

Hatzianastassiou, N., Wobrock, W., and Flossmann, A. I.: The effect of cloud-processing of aerosol particles on clouds and radiation, Tellus B, 50, 478-490, 1998.

Hatzianastassiou, N., Matsoukas, C., Drakakis, E., Stackhouse Jr., P. W., Koepke, P., Fotiadi, A., Pavlakis, K. G., and Vardavas, I.: The direct effect of aerosols on solar radiation based on satellite observations, reanalysis datasets, and spectral aerosol optical properties from Global Aerosol Data Set (GADS), Atmos. Chem. Phys., 7, 2585-2599, 2007, http://www.atmos-chem-phys.net/7/2585/2007/.

Haugen, D. A.: Effects of sampling rates and averaging periods on meteorological measurements, Proc. Fourth Symp. on Meteorological Observations and Instrumentation, Denver, CO, 15-18, 1978.

Held, A., Nowak, A., Wiedensohler, A., and Klemm, O.: Field measurements and size-resolved model simulations of turbulent particle transport to a forest canopy, J. Aerosol Sci., 37, 786-798, 2006.

Held, A., Niessner, R., Bosveld, F., Wrzesinsky, T., and Klemm, O.: Evaluation and Application of an Electrical low pressure impactor in disjunct eddy covariance aerosol flux measurements, Aerosol Sci. Tech., 41, 510-519, 2007.

Hendriks, D. M. D., Dolman, A. J., van der Molen, M. K., and van Huissteden, J.: A compact and stable eddy covariance set-up for methane measurements using off-axis integrated cavity output spectroscopy, Atmos. Chem. Phys., 8, 431-443, 2008, http://www.atmos-chem-phys.net/8/431/2008/.

Ito, K., Christensen, W. F., Eatough, D. J., Henry, R. C., Kim, E., Laden, F., Lall, R., Larson, T. V., Neas, L., Hopke, P. K., and Thurston, G. D.: PM source apportionment and health effects: 2. An investigation of intermethod variability in associations between source-apportioned fine particle mass and daily mortality in Washington, DC, J. Expo. Sci. Env. Epid., 16, 300-310, 2006.

Kerminen, V.-M., Pakkanen, T. A., Mäkelä, T., Hillamo, R. E., Sillanpää, M., Rönkkö T., Virtanen, A., Keskinen, J., Pirjola, L., Hussein, T. and Hämeri, K.: Development of particle number size distribution near a major road in Helsinki during an episodic 
inversion situation, Atmos. Environ., 41, 1759-1767, 2007.

Keskinen, J., Pietarinen, K., and Lehtimäki, M.: Electrical Low Pressure Impactor, J. Aerosol Sci. 23, 353-360, 1992.

Koren, I., Oreopoulos, L., Feingold, G., Remer, L. A., and Altaratz, O.: How small is a small cloud?, Atmos. Chem. Phys., 8, 38553864, 2008,

http://www.atmos-chem-phys.net/8/3855/2008/.

Kramm, G. and Dlugi, R.: Modelling of the Vertical Fluxes of Nitric Acid, Ammonia, and Ammonium Nitrate, J. Atmos. Chem., 18, 319-357, 1994.

Lenschow, D. H., Mann, J., and Kristensen, L.: How long is long enough when measuring fluxes and other turbulence statistics?, J. Atmos. Ocean. Tech., 11, 661-673, 1994.

Longley, I. D., Gallagher, M. W., Dorsey, J. R. and Flynn, M.: A case-study of fine particle concentrations and fluxes measured in a busy street canyon in Manchester, UK, Atmos. Environ., 38, 3595-3603, 2004.

Maricq, M., Podsiadlik, D., and Chase, R.: Examination of the SizeResolved and Transient Nature of Motor Vehicle Particle Emissions, Environ. Sci. Technol., 33, 1618-1626, 1999.

Marjamäki, M., Keskinen, J., Chen, D.-R., and Pui, D. Y. H.: Performance Evaluation of the Electrical Low-Pressure Impactor (ELPI), J. Aerosol Sci., 31, 249-261, 2000.

Marjmäki, M., Lemmetty, M., and Keskinen, J.: ELPI Response and Data Reduction I: Response Functions. Aerosol Sci. Tech., 39, 575-582, 2005.

Mårtensson, E. M., Nilsson, E. D., Buzorius, G., and Johansson, C.: Eddy covariance measurements and parameterisation of traffic related particle emissions in an urban environment, Atmos. Chem. Phys., 6, 769-785, 2006,

http://www.atmos-chem-phys.net/6/769/2006/.

Pakkanen, T. A., Makela, T., Hillamo, R. E., Virtanen, A., Ronkko, T., Keskinen, J., Pirjola, L., Parviainen, H., Hussein, T., and Hameri, K.: Monitoring of black carbon and size-segregated particle number concentrations at 9-m and 65-m distances from a major road in Helsinki, Boreal Environ. Res., 11, 296-310, 2006.

Panofsky, H. A. and Brier, G. W.: Some Applications of Statistics to Meteorology, The Pennsylvania State University Press, University Park, 224 pp., 1958.

Petelski, T.: Marine aerosol fluxes over open sea calculated from vertical concentration gradients, J. Aerosol Sci., 34, 359-371, 2003.

Pope, C. A. III, Burnett, R. T., Thun, M. J., Calle, E. E., Krewski, D., Ito, K., and Thurston, G. D.: Lung Cancer, Cardiopulmonary Mortality, and Long-term Exposure to Fine Particulate Air Pollution, J. Am. Med. Assoc., 287, 1132-1141, 2002.

Priestley, M. B.: Spectral Analysis and Time Series, Vol. 1 Univariate Series, Academic Press, London, 1981.

Pryor, S. C., Larsen, S. E., Sørensen, L. L., Barthelmie, R. J., Grönholm, T., Kulmala, M., Launiainen, S., Rannik, Ü., and Vesala, T.: Particle fluxes over forests: Analyses of flux methods and functional dependencies, J. Geophys. Res., 112, D07205, doi:10.1029/2006JD008066, 2007.

Pryor, S. C., Gallagher, M., Sievering, H., Larsen, S. E., Barthelmie, R. J., Birsan, F., Nemitz, E., Rinne, J., Kulmala, M., Grönholm, T., Taipale, R., and Vesala, T.: A review of measurement and modelling results of particle atmosphere-surface exchange, Tellus B, 60, 42-75, 2008.

Rinne, H. J. I., Delany, A. C., Greenberg, J. P., and Guenther, A.
B.: A true eddy accumulation system for trace gas fluxes using disjunct eddy sampling method., J. Geophys. Res., 105, $24791-$ 24 798, 2000.

Rinne, J., Douffet, T., Prigent, Y., and Durand, P.: Field comparison of disjunct and conventional eddy covariance techniques for trace gas ?ux measurements, Environ. Pollut., 152, 630-635, 2008.

Ruuskanen, T. M., Kaasik, M., Aalto, P. P., Hõrrak, U., Vana, M., Måartensson, M., Yoon, Y. J., Keronen, P., Mordas, G., Ceburnis, D., Nilsson, E. D., O’Dowd, C., Noppel, M., Alliksaar, T., Ivask, J., Sofiev, M., Prank, M., and Kulmala, M.: Concentrations and fluxes of aerosol particles during the LAPBIAT measurement campaign at Värriö field station, Atmos. Chem. Phys., 7, 3683-3700, 2007,

http://www.atmos-chem-phys.net/7/3683/2007/.

Schmidt, A., Wrzesinsky, T., and Klemm, O.: Gap Filling and Quality Assessment of $\mathrm{CO}_{2}$ and Water Vapour Fluxes above an Urban Area with Radial Basis Function Neural Networks. Bound.-Lay. Meteorol., 126, 389-413, 2008.

Schwartz, J., Dockery, D. W., and Neas, L. M.: Is daily mortality associated specifically with fine particles?, J. Air. Waste Manage., 46, 927-939, 1996.

Seinfeld, J. H. and Pandis, S. N.: Atmospheric Chemistry and Physics: From Air Pollution to Climate Change, Second Edition, J. Wiley, New York, 2006.

Stull, R. B.: An Introduction to Boundary Layer Meteorol., Dordrecht, Boston, London, Kluwer Acad. Publ., 666 pp., 1988.

VanReken, T. M., Rissman, T. A., Roberts, G. C., Varutbangkul, V., Jonsson, H. H., Flagan, R. C., and Seinfeld, J. H.: Toward aerosol/cloud condensation nuclei (CCN) closure during CRYSTAL-FACE, J. Geophys. Res., 108(D20), 4633, doi:10.1029/2003JD003582, 2003.

Velasco, E., Pressley, S., Allwine, E., Westberg, H., and Lamb, B.: Measurements of $\mathrm{CO}_{2}$ fluxes from the Mexico City urban landscape, Atmos. Environ., 39, 7433-7446, 2005.

Virtanen, A., Marjamäki, M., Ristimäki, J., and Keskinen, J.: Fine particle losses in electrical low-pressure impactor, J. Aerosol Sci., 32, 389-401, 2001.

Vogt, R., Christen, A., Rotach, M. W., Roth, M., and Satyanarayana, A. N. V.: Temporal dynamics of $\mathrm{CO}_{2}$ fluxes and profiles over a Central European city, Theor. Appl. Climatol., 84, 117-126, 2006.

Vong, R. J., Vickers, D., and Covert, D. S.: Eddy correlation measurements of aerosol deposition to grass, Tellus, 56B, 105-117, 2004.

Webb, E. K., Pearman, G. I., ans Leuning, R.: Correction of the flux measurements for density effects due to heat and water vapour transfer, Q. J. Roy. Meteor. Soc., 106, 85-100, 1980.

Wilczak, J. M., Oncley, S. P., and Stage, S. A.: Sonic anemometer tilt correction algorithms, Bound.-Lay. Meteorol., 99, 127-150, 2001.

Yu, H., Kaufman, Y. J., Chin, M., Feingold, G., Remer, L. A., Anderson, T. L., Balkanski, Y., Bellouin, N., Boucher, O., Christopher, S., DeCola, P., Kahn, R., Koch, D., Loeb, N., Reddy, M. S., Schulz, M., Takemura, T., and Zhou, M.: A review of measurement-based assessments of the aerosol direct radiative effect and forcing, Atmos. Chem. Phys., 6, 613-666, 2006, http://www.atmos-chem-phys.net/6/613/2006/. 